\title{
Trabalho e reestruturação produtiva no Brasil neoliberal - Precarização do trabalho e redundância salarial
}

\section{Giovanni Alves}

Universidade Estadual Paulista (Unesp), Marília

Trabalho e reestruturação produtiva no Brasil neoliberal - Precarização do trabalho e redundância salarial

Resumo: O objetivo do artigo é tratar das mutações sociais que ocorrem no mundo do trabalho a partir da era neoliberal no Brasil. Examina-se a precarização do trabalho como sendo elemento compositivo do novo metabolismo social que emerge com a reestruturação produtiva do capital e a constituição do Estado neoliberal. Apresenta-se como bases objetivas da precarização do trabalho, a intensificação (e ampliação) da exploração (e espoliação) da força de trabalho, o desmonte de coletivos de trabalho e de resistência sindical-corporativa; assim como a fragmentação social nas cidades em virtude do crescimento exacerbado do desemprego em massa.

Palavras-chave: trabalho, capitalismo, reestruturação produtiva, sindicalismo.

Work and Productive Restructuring in Neoliberal Brazil - Precariousness of Work and Salary Redundancy

Abstract: The purpose of this article is to analyze the social mutations that occur in the world of labor based on the neoliberal era in Brazil. It examines the precariousness of work as being an element that composes the new social metabolism that emerges with the productive restructuring of capital and the constitution of the neoliberal State. It presents as the objective causes of the increased precariousness of work the intensification and expansion of the exploitation and plundering of the labor force, the dismounting of labor collectives and of corporate-union resistance; as well as the social fragmentation in the cities due to the exacerbated growth of mass unemployment.

Key words: labor, capitalism, productive restructuring, unionism. 


\section{Introdução}

Esta pesquisa focaliza a experiência da precarização do trabalho como um processo constitutivo do novo metabolismo social que se manifesta da reestruturação produtiva do capital e da formação do Estado neoliberal no país. A base objetiva da precarização do trabalho se caracteriza pela intensificação (e a ampliação) da exploração (e a espoliação) da força de trabalho, pelo desmonte de coletivos de trabalho e de resistência sindical-corporativa; e pela fragmentação social nas cidades em virtude do crescimento exacerbado do desemprego em massa.

No tocante à metodologia de pesquisa, este ensaio é produto de pesquisa bibliográfica e reflexão crítica, a partir de dados quantitativos obtidos nas estatísticas sociais do IBGE e DIEESE/SEADE, dos quais buscamos organizar alguns elementos teóricocategoriais necessários para a apreensão crítica do tema do "metabolismo social da precarização do trabalho no Brasil" nas últimas décadas. Por isso, salientamos a importância de apreendermos a precarização do trabalho enquanto "experiência vivida" e "experiência percebida" de individualidades pessoais da classe do proletariado.

Utilizamos a categoria de "experiência" - desdobrada em "experiência vivida" e "experiência percebida" - sugerida por E. P. Thompson (THOMPSON, 1963). A "experiência percebida" (que muitos identificam imediatamente à palavra "experiência") diz respeito à exposição de relatos de vida de sujeitos/agentes assalariados - assujeitados pelo salariato - em processo de reestruturação. Ela se move na direção do que Marx denominou "consciência social" (muitos afirmam que a "experiência percebida" é um meio imperfeito e falsificador, corrompido por interferências ideológicas).

Por outro lado, a "experiência vivida" vincula-se às regularidades no interior do ser social, que, com frequência, resultam de causas materiais e que ocorrem de forma independente da consciência ou da intencionalidade. Tais causas, inevitavelmente, dão ou devem dar origens à "experiência vivida" da classe. A pressão dessas causas sobre a totalidade do campo da consciência, não pode ser adiada, falsificada ou suprimida indefinidamente pela ideologia. Diz Thompson (1963, p. 203):

A experiência chega sem bater na porta e anuncia mortes, crises de subsistência, guerras, desemprego, inflação, genocídio. Pessoas passam fome: os que sobrevivem pensam o mercado de outra forma. Pessoas são presas: na prisão meditam na lei de novas maneiras. [...] Dentro do ser social ocorrem mudanças que dão origem a uma experiência transformada: e essa experiência é determinante, no sentido de que exerce pressão sobre a consciência social existente, propõe novas questões e oferece gran- de parte do material com que lidam os exercícios intelectuais mais elaborados.

E mais adiante observa:

A experiência I [experiência vivida] está em eterna fricção com a consciência imposta e, quando ela irrompe, nós, que lutamos com todos os intrincados vocabulários e disciplinas da experiencia II [experiência percebida], podemos experenciar alguns momentos de abertura e de oportunidade, antes que se imponha mais uma vez o molde da ideologia.

Dessa forma, a "experiência", "sem bater na porta", constitui e nega, opõe e resiste, estabelece mediações, é espaço de prática, intervenção, obstaculalização, recusa, é processo de formação de identidades de classe e, poderíamos acrescentar, de gênero, geracional e de etnias. Processos dialeticamente articulados que, ela, a experiência, expressa de forma privilegiada. Deste modo, Thompson distancia-se, como se vêm do conceito vulgar de "experiência" que estabelece sua equivalência meramente com a empiria.

Portanto, a "experiência da precarização" implica "experiência percebida" e "experiência vivida", processos dialeticamente articulados, que se impõem aos sujeitos/agentes assalariados em processo de reestruturação. Parafraseando Thompson (1963, p. 208), podese dizer que "pessoas sofrem a experiência de precarização: os que sobrevivem (e os que são desligados) pensam o trabalho assalariado de outra maneira,"

Ao contrapor "percebido" e "vivido" no plano da experiência, contraposição dialeticamente articulada, Thompson traduz a ideia marxiana que nos diz "eles fazem, mas não o sabem". A experiência, diz Thompson, "sem bater na porta", nos provoca a "dar respostas", ato ontologicamente primordial do ser social (diz Lukács (1981) que o "homem é um ser que dá resposta").

\section{A experiência da precarização do trabalho}

A experiência da precarização do trabalho no Brasil decorre da síndrome objetiva da insegurança de classe (insegurança de emprego, de representação, de contrato etc) que emerge numa textura histórica específica - a temporalidade neoliberal. Ela é elemento compositivo do novo metabolismo social que emerge a partir da constituição do Estado neoliberal. Possui como base objetiva, a intensificação (e a ampliação) da exploração (e a espoliação) da força de trabalho e o desmonte de coletivos de trabalho e de resistência sindical-corporativa; além, é claro, da fragmentação social nas cidades, em virtude do crescimento exacerbado do desemprego total e a deriva pessoal no tocante a perspectivas de carreira e de 
trabalho devido à ampliação de um precário mercado de trabalho (ALVES, 2007).

Na medida em que se rompem resistências sociais e políticas do trabalho organizado (politicamente, com a derrota da Frente Brasil Popular, em 1989; e socialmente, com a desagregação social da classe em virtude da recessão da economia sob o governo Collor), ampliam-se as bases objetivas (e subjetivas) da sua precarização, constituindo o que denominamos de síndrome da precarização do trabalho, complexo objetivo de determinações que dão origem, na década de 1990, às experiências vividas e às experiências percebidas da precarização do trabalho. Eis o sentido da globalização - a partir de 1990, o Brasil incorpora-se na dinâmica de um processo estrutural de precarização da classe do trabalho que marca a nova ordem sociometabólica do capital no plano mundial.

$\mathrm{Na}$ virada para a década de 1990, as reformas neoliberais implementadas a partir do governo Collor e o cenário macroeconômico (recessão ou baixo crescimento da economia num contexto de intensa reestruturação industrial, juros elevados e abertura comercial com a intensificação da concorrência intercapitalista), contribuíram para a constituição de um cenário de degradação do mercado de trabalho com alto índice de desemprego total nas regiões metropolitanas e deterioração dos contratos salariais devido à expansão da informalização e da terceirização nas grandes empresas, visando reduzir custos.

O metabolismo social da precarização do trabalho, constituído pelo processo objetivo de degradação salarial e pela pletora de experiências pessoais de desligamentos do salariato regulado, é marcado não apenas pelo cenário interno de reformas capitalistas, mas também pelo cenário externo de intensa reação neoliberal de cariz político-ideológico (os acontecimentos históricos da Queda do Muro de Berlim em 1989, e o fim da URSS, em 1991, tornaram-se ícones midiáticos para a proclamação da vitória gloriosa da globalização capitalista). É nessa época que se articula a hegemonia neoliberal na América Latina, com o Brasil sendo elemento-chave do "Consenso de Washington".

Aliás, o elemento ideológico é, em si, uma mediação fundamental (e fundante) da "experiência percebida" da classe do trabalho, na medida em que contribui para instaurar o conteúdo ideacional dos novos métodos de gestão de cariz toyotista. Métodos baseados no envolvimento participativo de operários e empregados e, no plano da reprodução social, dos novos modos de sociabilidade, organizados a partir dos valores-fetiches, expectativas e utopias de mercado. Na medida em que se dissemina sob a era neoliberal, a ideologia de mercado, com suas implicações na prática social (e coletiva), "precariza-se", de certo modo, a "experiência percebida" (ou a consciência social) da classe do proletariado.
No Brasil, a derrota do candidato da Frente Brasil Popular, Luis Inácio Lula da Silva, do Partido dos Trabalhadores (PT), em 1989, e a vitória de Fernando Collor de Melo explicitam uma alteração qualitativamente nova do cenário da luta de classes no país. Abriuse espaço para o avanço do receituário neoliberal em 1990, implementando-se políticas que impulsionaram a reestruturação capitalista no país. Para o mundo do trabalho, tornou-se bastante adverso o cenário social e político devido à política autocrática do governo Collor visando destruir o sindicalismo, principalmente de categorias organizadas que resistiam a medidas drásticas que atingiam direitos do trabalho (no caso de empresas estatais e setor público).

\section{O desmonte do sindicalismo do confronto}

Na década de 1990, ocorre uma mudança substantiva na dinâmica (e forma de ser) das greves no Brasil que apontam para tendências novas, em contraste com a década anterior, indicando, deste modo, uma nova dinâmica da prática sindical-corporativa ou prática sindical propriamente dita. Na verdade, as dificuldades de "greves gerais" por categoria e a disseminação de greves por empresas no decorrer da "década neoliberal", expressam condições objetivas adversas de precarização do mercado de trabalho e de ofensiva do capital na produção.

A partir de 1990, ocorre uma inflexão significativa no total de greves no Brasil (em contraste com o período de ascensão do sindicalismo, de 1985 a 1989). Há uma conjuntura histórico-política, marcada pela política neoliberal que articula controle social de mercado (a recessão da economia brasileira do governo Collor, que ampliou o desemprego total nas regiões metropolitanas, colocou sérias dificuldades para o movimento sindical classista) e dispositivos autocrático-estatais de controle do sindicalismo público, um dos polos combativos contra o neoliberalismo na década de 1990.

Após o descenso de 1991 e 1992, o total de greves tende a crescer relativamente, a partir de 1993, embora não consiga retomar a dinâmica ascendente da década passada. Na verdade, ocorre, nesse período, uma alteração significativa na morfologia social das greves. É importante ressaltar que o Plano Real, de 1994, que extinguirá a política salarial, coloca novos parâmetros para a negociação coletiva no país.

Aliás, desde o início da década de 1990, os grandes empresários privados, acompanhando a ofensiva neoliberal no plano da gestão macroeconômica e reorganização patrimonial do Estado brasileiro (com a privatização das empresas estatais e abertura das Reformas do Estado: Reforma da Previdência, Reforma Administrativa, Reforma Tributária,etc, agenda política que percorria a era neoliberal), promovem uma importante ofensiva nas negociações coletivas 
de trabalho que atinge o metabolismo social da luta sindical classista. A nova postura do grande capital é descentralizar o processo de negociação e flexibilizar os conteúdos dos acordos e convenções coletivas de trabalho (CAPPA, 2000).

A descentralização das negociações coletivas, que teve nas redefinições do Grupo 14 da FIESP no início dos anos 1990, foi um dos principais sinalizadores da ofensiva patronal que contribuiu para alterar de forma significativa a morfologia social das greves, ativando tendências neocorporativas no seio do movimento sindical, ou seja, práticas sindicais de natureza concertativa circunscritas ao âmbito da empresa ou do local de trabalho.

Assim, apesar de manter a negociação na mesma data base, o Grupo 14 da FIESP subdvidiu-se em três: a) o Grupo 5, que reunia os sindicatos das montadoras, autopeças, parafusos, forjaria e fundição; b) Grupo 8, que reúne os sindicatos de máquinas, trefilação e laminação de metais ferrosos e os dos não ferrosos, aparelhos elétricos e eletrônicos, refrigeração, condutores elétricos, indústria de metais e equipamentos ferroviários e rodoviários e balanças, pesos e medidas: e c) o Grupo 10, coordena- do pela FIESP, que reúne dez sindicatos pequenos como, por exemplo, os de mecânica, funilaria e móveis de metal, reparação de veículos e refrigeração. Progressivamente, a subdivisão dos grupos econômicos foi aumentada, pois, até fins de 1998 totalizavam sete: a) Grupo dos sindicatos das montadoras; b) Grupo dos 3 (sindicatos das autopeças, parafusos e forjaria); c) Grupos 8 e 10 foram mantidos; d) os sindicatos das empresas de fundição, esquadrias metálicas e siderúrgicas optaram por estabelecer negociações coletivas de forma isolada (CAPPA, 2000).

Por isso, a "força das circunstâncias" da "década neoliberal", caracterizada pela desestruturação do mercado de trabalho por conta das políticas macroeconômicas neoliberais, e pela fragmentação das negociações coletivas, imposta pelo patronato, obriga o sindicalismo a abandonar as greves gerais por categoria e voltar-se para greves por empresa. Apesar da retomada relativa das mobilizações grevistas em 1993, conforme Figura 1, diminui de forma paulatina, o número de grevistas (tendência de decrescimento que percorre a década de 1990, intensificando-se na última metade da década passada), conforme Figura 2.

\section{Figura 1 - Total de greves no Brasil (1985-1999)}

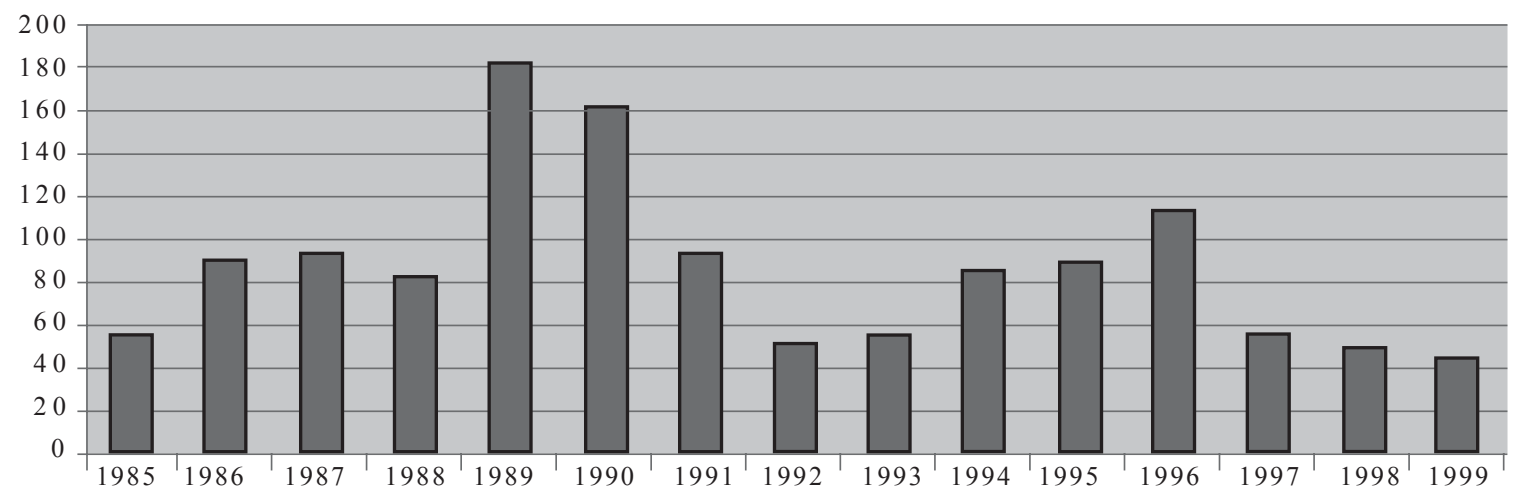

Fonte: DIEESE (2002).

Figura 2 - Grevistas no Brasil - Média mensal por ano (1985-1999)

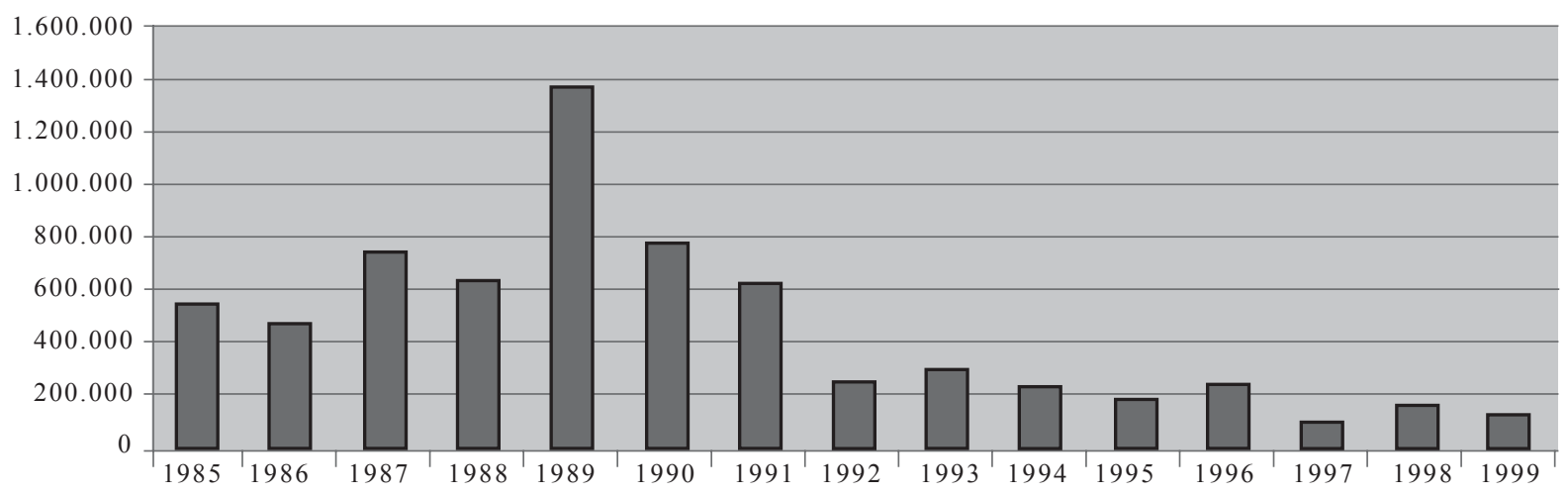

Fonte: DIEESE (2002). 
Na verdade, a nova temporalidade histórica do capital, marcada pela precarização do trabalho no Brasil, tende a reconverter a "cultura de greve" para o âmbito das empresas. Consolida-se um defensivismo de novo tipo que irá marcar a cultura sindical sob a era neoliberal. A nova territorialidade das greves, restritas à empresa e não mais à dimensão da categoria de trabalhadores assalariados (ou mesmo da classe social) é expressão da nova morfologia social da precarização do trabalho. Esta "nova ordenação socioespacial" das greves é um traço explícito do particularismo sindical-corporativo em seus rebatimentos territoriais, que contribui para alimentar a ideologia do sindicalismo propositivo (ALVES, 2007).

É importante destacar não apenas a nova "forma de ser" das greves, mas o novo conteúdo das reivindicações sindicais. Elas também sofrem alterações significativas que traduzem a ofensiva do capital na produção (a partir de 1994, cresce o número de greves por não cumprimento de direitos). Tal como a nova ordenação socioespacial das greves, o conteúdo das reivindicações sindicais assumem, nesse período, traços do "defensivismo de novo tipo". Na verdade, o que se busca é preservar direitos ameaçados pela nova dinâmica da "acumulação por espoliação" que é própria do Estado neoliberal (HARVEY, 2004).

A partir do Plano Real, em 1994, plano de estabilização monetário que inaugura, de fato, sob a injunção neoliberal, a nova temporalidade histórica do capital no país, retomam-se as greves, embora elas fiquem restritas às empresas, mobilizando um pequeno contingente de trabalhadores grevistas. Na mesma medida, no período, crescem as greves por não cumprimento de direitos trabalhistas, demonstrando o avanço paulatino do processo de precarização do trabalho em categorias assalariadas organizadas (segundo o DIEESE, ao lado dessas, crescem, no período de 1993 a 1999, as greves: por emprego, de $12 \%$ para $28 \%$; pela jornada de trabalho, de $3 \%$ para $10 \%$; e por motivo sindical, de $5 \%$ para $10 \%$ ) (DIEESE, 2002).

$\mathrm{Na}$ verdade, tais indicadores dos motivos de greves explicitam os elementos compositivos da síndrome da precarização do trabalho que atinge categorias de assalariados na década de 1990: usurpação de direitos trabalhistas, insegurança no emprego, usurpação do tempo de vida pelo tempo de trabalho (conteúdo das greves por jornada de trabalho) e restrição do direito de associação sindical (conteúdo das greves por motivo sindical).

Assim, as condições materiais objetivas (e subjetivas) instauradas pela nova temporalidade histórica do capital, determinaram as condições de luta sindical e política, como as negociações coletivas segmentadas e a fragmentação do estatuto salarial, agravando os "elementos de inércia" da lógica do particularismo corporativista intrínseco à estrutura sindical no Brasil (o que explica sua continuidade no decorrer da primeira metade da década de 2000).
Um dos elementos objetivos de ampla significação que marcam a precarização do trabalho no Brasil foi a perda - no imaginário social - de referentes coletivos. Nesse sentido, a década de 1990 parece ser o reverso da década anterior, sua antítese, isto é, negação da afirmação coletiva propiciada pelo sindicalismo e associativismo dos anos 1980. Embora tenha ocorrido o crescimento do número de sindicatos de trabalhadores no país - segundo o IBGE (BRASIL, 2003, online) ele cresceu 49,16\% entre 1991 e 2001 -, isso não se traduziu em efetiva representação política e constituição de referentes coletivos para o mundo do trabalho. $\mathrm{O}$ crescimento de sindicatos nesta década atesta apenas o grau de fragmentação sindical-corporativa que se exacerbou na "década neoliberal" (embora segundo o IBGE, tenha aumentado em $0,8 \%$ o número de pessoas sindicalizadas em relação ao total de trabalhadores: 26,01\%; verifica-se, pelos dados expostos, a diminuição do total de grevistas e a alteração dos motivos das greves).

Deve-se salientar também um dado estrutural relevante: a diminuição no decorrer da década de 1990, de empregos gerados pelo setor industrial - com destaque para o setor metal-mecânico. É na indústria, ao contrário dos serviços e comércio, que temos os setores melhores organizados - geralmente melhor pagos e melhor qualificados do mundo do trabalho (em 1989, os postos de trabalho no setor industrial representavam 33\% na região metropolitana de São Paulo e, ao final do período analisado, esta parcela reduziu-se para 20\%; no caso do setor metal-mecânico na região metropolitana de São Paulo, reduziuse em quase $50 \%$ a geração de postos de trabalho). Foi a partir da década de 1990 que o setor de serviços, que já era na década de 1980 o principal responsável no total de postos gerados, passou de 41,3\%, em 1989, para 52,3\%, em 2001 (a proporção das ocupações geradas no comércio passou de $14,8 \%$ para $16,2 \%$ ). Entretanto, no setor de serviços, há uma notável exceção: os serviços creditícios e financeiros não elevaram sua participação no total das ocupações de serviço, mas, pelo contrário, reduziramna, de 4,0\% (em 1989) para 2,3\% (DIEESE, 2002).

\section{A economia da sociabilidade constrangida}

A reforma neoliberal, a partir do governo Collor, significou alterações substantivas na dinâmica da economia brasileira e, por conseguinte, na forma de ser do mercado de trabalho. O Brasil inseriu-se de forma subalterna no processo de mundialização do capital. A adoção de políticas neoliberais submeteu o país à lógica da financeirização vigente no capitalismo global. Constituiu-se o que poderíamos denominar de "economia da sociabilidade constrangida", tendo em vista que, sob a "ditadura dos credores", os 
gestores da política macroeconômica colocaram, como foco privilegiado, a estabilização monetária por vias ortodoxas (juros elevados para atrair capital estrangeiro e garantir o fechamento do balanço de pagamento) com impactos perversos no crescimento da economia, e, por conseguinte, no mercado de trabalho (a degradação do metabolismo social do trabalho e, portanto, a "tessitura de uma sociabilidade constrangida", expressou-se, como demonstraremos a seguir, nos indicadores socioestatísticos do crescente desemprego total, na expansão dos contratos precários, na queda dos rendimentos médios do trabalho e na perda de referentes coletivos).

A política neoliberal de abertura comercial do governo Collor, que prossegue no decorrer da década sob os governos Itamar Franco e Fernando Henrique Cardoso, significou a destruição de cadeias produtivas na indústria brasileira, com empresas sendo fechadas por não conseguirem concorrer com produtos estrangeiros, e, portanto, o crescimento do desemprego de massa. Nesse período, as grandes empresas foram obrigadas a intensificar a reestruturação produtiva colocando o sindicalismo na defensiva diante do cenário hostil - governos anti-sindicalistas e recessão econômica com desemprego crescente.

Depois do período recessivo do governo Collor (1990-1992), a economia brasileira tem uma pequena retomada em virtude dos efeitos positivos da estabilização monetária propiciada pelo Plano Real. Entretanto, o crescimento da economia brasileira não se sustentou diante das vulnerabilidades da política econômica neoliberal e dos influxos da crise dos mercados mundiais (a partir de 1995, com a crise mexicana e logo a seguir, em 1996, com a crise asiática). Por isso, na década de 1990, o PIB tem trajetória incerta e crescimento medíocre.

Por conseguinte, na medida em que a política econômica neoliberal constrange o crescimento e o investimento produtivo no mercado interno (o que é a lógica da mundialização financeira), ela contribui para a degradação paulatina do mercado de trabalho, como demonstra o crescimento significativo do desemprego total nas regiões metropolitanas.

Observa-se, no decorrer da década de 1990, três conjunturas da economia brasileira: a primeira, sob o governo Collor, é marcada pela intensa recessão (1990-1992); a segunda, sob o governo Itamar (19931994), e primeiros anos do governo Cardoso (19951996), é marcada por uma pequena retomada da atividade da economia sob os influxos positivos dos pri- meiros anos do Plano Real; e a terceira (1997-1999), nos últimos anos do primeiro mandato do governo Cardoso, e no primeiro ano de seu segundo mandato presidencial, é marcada pela crise da economia global, expondo, deste modo, as incertezas e vulnerabilidades da economia brasileira diante da conjuntura internacional.

É importante salientar que, no aspecto conjuntural, o Plano Real, de 1994, imprimiu uma significativa inflexão no processo de desenvolvimento capitalista no país, na medida em que estabilizou a moeda corroída pela hiperinflação crônica, alterando as expectativas dos agentes econômicos e, por conseguinte, a morfologia da economia real. É com o sucesso do Plano Real em estabilizar a economia brasileira que alterações estratégicas - e não mais defensivo-reativas - ocorrem nas empresas, num cenário de intensa concorrência dos múltiplos capitais. Nessa época, altera-se o ambiente de trabalho nas empresas (amplia-se, por exemplo, a disseminação de novas práticas de gestão sob o espírito do toyotismo e adotamse novas tecnologias de produção). Instaura-se nas grandes empresas no país, o que denominamos de "toyotismo sistêmico" (ALVES, 2000); além disso, como salientamos antes, altera-se, a morfologia das lutas sindicais das categorias de trabalhadores assalariados organizados, com a mudança de conteúdo da pauta da negociação coletiva. Com a estabilização monetária e a redução drástica da inflação, extingue-se a política salarial, colocando os sindicatos de trabalhadores diante de um menu reivindicativo centrado em demandas particularistas restritas à empresa (como, por exemplo, as negociações da PLR - Participação em Lucro e Resultado). É claro que o cenário de desemprego de massa coloca imensas dificuldades para a barganha sindical.

Na década de 1990, outro elemento objetivo da precarização estrutural de classe do trabalho foi o Programa Nacional de Desestatização (PND), criado em 1991, que contribuiu para transferência de patrimônio social para o setor privado. O processo de privatização, que marcou a era neoliberal, como elemento de reforma do Estado, significou o fortalecimento da acumulação de capital no país, embora tenha contribuído, ao mesmo tempo, para a acumulação por espoliação, que não implica necessariamente em investimento produtivo (ela significou a degradação - ou mesmo extinção - do estatuto salarial de importantes categorias de trabalhadores públicos, como bancários de bancos estaduais, ope- 
rários de siderúrgicas e mineradores estatais, trabalhadores do sistema de telefonia e em alguns casos do sistema de eletricidade etc). Por outro lado, a Reforma Administrativa do Estado sob a gestão neoliberal significou a precarização do trabalho do assalariado do setor público.

\section{O espectro da redundância}

Apesar da flutuação conjuntural da economia brasileira, verificada na década de 1990, com impactos na variação anual do PIB, é contínua a linha de degradação do mercado de trabalho. De forma significativa, a partir de 1995, verifica-se o crescimento do desemprego total nas regiões metropolitanas (utilizamos como exemplo típico, a Região Metropolitana de São Paulo (RMSP), uma das regiões mais dinâmicas da economia brasileira). Nos anos de 1993 e 1994, verifica-se uma pequena queda do desemprego total na RMSP (sem recuperar, no entanto, o patamar de 1989). Após 1995, ele dispara, mantendose num patamar elevado, conforme a Figura 3.

Utilizamos o índice de desemprego total ao invés do desemprego aberto pela sua capacidade de expressar a amplitude da degradação do mundo do trabalho metropolitano. $\mathrm{O}$ desemprego total expressa a soma dos desempregos aberto e oculto. O desemprego aberto refere-se às pessoas que procuraram trabalho de maneira efetiva nos 30 dias anteriores ao da entrevista e não exerceram nenhum tipo de atividade nos sete últimos dias. O desemprego oculto corresponde às seguintes situações: a) desemprego oculto pelo trabalho precário, em que pessoas, para sobreviver, exerceram algum trabalho de auto-ocupação, de forma descontínua e irregular, ainda que não remunerada em negócios de parentes e, além disso, tomaram providências concretas, nos 30 dias anteriores ao da entrevista, ou em até 12 meses atrás, para conseguir um trabalho diferente deste; b) de- semprego oculto pelo desalento, em que as pessoas não possuem trabalho e nem procuraram nos últimos 30 dias, por desestímulos do mercado de trabalho ou por circunstâncias fortuitas, mas apresentaram procura efetiva de trabalho nos últimos 12 meses.

A partir de 1996, verifica-se um movimento de inflexão descendente e queda significativa do rendimento real dos trabalhadores assalariados, num cenário de estagnação da economia brasileira e crescente índice de desemprego total. Ocorre a queda paulatina dos rendimentos dos trabalhadores autônomos, constituídos em sua maior parte por assalariados informalizados (na medida em que ocorre um processo crescente de terceirização de atividades industriais e serviços, o maior contingente de trabalhadores autônomos expressa tão somente a crescente mancha de assalariados precarizados).

Portanto, sob a nova temporalidade do capital, ocorre a expansão da mancha de trabalhos precarizados na década de 1990. Assim, por exemplo, no período de 1989-2001, na Região Metropolitana de São Paulo, tivemos um pequeno crescimento do trabalho assalariado. Ao mesmo tempo, verifica-se que o crescimento deveu-se ao crescimento do trabalho assalariado "sem carteira" - a maior parte deles no setor de serviços e comércio (o assalariamento sem carteira significa trabalhadores assalariados excluídos dos direitos trabalhistas).

Deste modo, no decorrer da "década neoliberal", ao lado do crescimento do desemprego total, constatamos a expansão significativa de contratos de assalariamento precário (com impactos é claro, na queda dos rendimentos médios reais). Assim, verifica-se que o crescimento de contratos assalariados sem carteira ocorre, de forma significativa, a partir de 1996, período de inflexão descendente do índice de rendimentos real do trabalho assalariado. Um detalhe: apesar da "década neoliberal", o emprego assalariado no setor público não apresentou, no período, uma queda significativa.

\section{Figura 3 - Taxa de desemprego total - Região Metropolitana de São Paulo (1985-2001)}

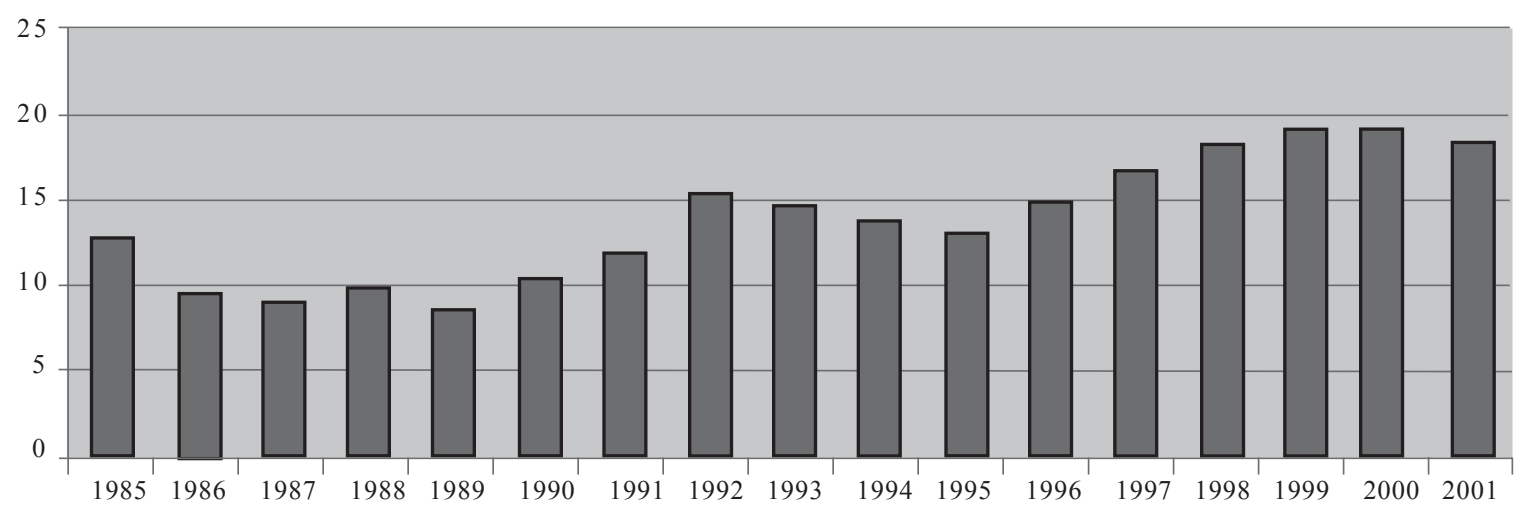

Fonte: DIEESE (2002) . 
No período da "década neoliberal" ganhou força na RMSP, a "terceirização", com a contratação de empresas prestadoras de serviço e a de trabalhadores autônomos. Embora o maior percentual de contratação salarial ainda sejam as contratações não flexibilizadas (que decresceu de 79,1\%, em 1989, para $64,6 \%$, em 2001), a contratação flexibilizada, no decorrer da década de 1990, cresceu mais de 50\%.

É importante ressaltar que a contratação assalariada precária envolve não apenas o assalariamento sem carteira (inclusive no setor público), mas a utilização de formas flexíveis de trabalho nas empresas privadas e setor público. Mesmo no setor público, a estatística social constatou o crescimento em 50\% de contratação sem carteira assinada; o que talvez explique porque o emprego assalariado não teve uma queda significativa nesse setor. Isto é, o setor público, por conta das demandas sociais crescentes, não conseguiu ser "enxugado" de forma significativa pelas gestões neoliberais. Entretanto, em contrapartida, buscou-se precarizar o estatuto salarial do emprego público. O crescimento de $50 \%$ nas contratações assalariadas sem carteira e o recurso aos serviços terceirizados, que crescem também de forma significativa no período, embora não sejam discriminados entre setor privado e setor público, atestam com vigor, a tese da precarização paulatina do emprego público na RMSP.

De fato, no período da década de 1990, constatamos uma tendência de degradação do estatuto salarial, Tabela 1, que coloca no horizonte de experiências da classe dos trabalhadores assalariados, a perspectiva (ou expectativa) da precarização do trabalho. Na verdade, a "experiência da precarização do trabalho" diz respeito não apenas a ocorrências que atingem hic et nunc (aqui e agora) o estatuto salarial de homens e mulheres assalariados, mas envolve expectativas socialmente postas pelo desenvolvimento do mercado de trabalho.
O espectro da redundância que emerge com a sociabilidade constrangida na "década neoliberal" torna-se uma ameaça real ou imaginária para o contingente de trabalhadores e trabalhadoras ainda sob contratos não flexibilizados. Por exemplo, mesmo que a contratação flexibilizada tenha atingido, em 2001, o percentual de $35,4 \%$ da população ocupada ("apenas" $1 / 3$ da força de trabalho ocupada na RMSP de qualquer forma, ainda não é a maioria), os demais 64,6\% sentem-se "ameaçados" pelo espectro da redundância crescente do trabalho precário. No plano psicossocial, onde se constrói as experiências vividas e experiências percebidas da precarização do trabalho, a ameaça - mesmo que imaginária - é fator de medo, afeto regressivo que articula, no âmbito da tessitura social, os consentimentos espúrios que ocorrem no plano da sociabilidade constrangida (ALVES, 2007).

\section{Jornada de trabalho: tempo de trabalho manifesto e tempo de trabalho oculto}

Além da contratação assalariada, elementos da precarização do trabalho atingem a jornada de trabalho. Aliás, sob a década neoliberal, a delimitação da jornada de trabalho tornou-se um campo de luta. A pressão por horas extras - muitas delas, não pagas e a extensão do tempo de trabalho consumindo o tempo de vida pessoal-familiar tornou-se uma das preocupações candentes dos trabalhadores assalariados da indústria, serviços e comércio.

No livro Salário, preço e lucro, Marx (1988) observou que "o tempo é o campo de desenvolvimento humano". Na medida em que tempo de vida se interverte em tempo de trabalho, ocorre a perda de espaços de sociabilidade humano-social. A luta pela redução da jornada de trabalho tornou-se luta fundamental pelo desenvolvimento humano-social.

Tabela 1 - Salário mensal médio segundo setores de atividade econômica - Região Metropolitana de São Paulo (em reais, de janeiro 2000)

\begin{tabular}{|c|c|c|c|}
\hline Setores & 1989 & 1999 & Variação (em\%) \\
\hline Total dos Empregados (1) & 1.020 & 828 & $-18,8$ \\
\hline Indústria & 1.163 & 967 & $-16,8$ \\
\hline Construção Civil & 964 & 757 & $-21,5$ \\
\hline Comércio & 847 & 646 & $-23,7$ \\
\hline Serviços (2) & 1.097 & 953 & $-13,1$ \\
\hline Empregados Domésticos & 257 & 324 & 26,1 \\
\hline
\end{tabular}

Fonte: DIEESE (2001).

(1) Os empregados incluem os assalariados, os empregados domésticos assalariados e os empregados domésticos contratados por tarefa.

(2) Inclui a administração pública. 
Na década de 1990, sob a pressão do mercado, avassalou-se o tempo de vida social de operários e empregados assalariados, na medida em que o tempo de trabalho - seja o "tempo de trabalho manifesto" (regulamentado pela legislação trabalhista, que trata da jornada de trabalho; e constatado por meio das estatísticas sociais), ou o "tempo de trabalho oculto", em suas múltiplas formas, do longo deslocamento do local de moradia aos locais de trabalho, às tarefas e preocupações que acompanham os operários ou empregados assalariados em seu tempo de descanso - colonizou o tempo de vida.

Observa-se, segundo dados do estudo DIEESE/ SEADE, citados em Hoffman e Mendonça (2003), que embora tenha havido, na década de 1990, redução da jornada semanal média de trabalho (de 44 para 43 horas) - que, de fato, expressa mais uma queda do dinamismo da geração de postos de trabalho assalariado, que a melhoria da qualidade de vida dos assalariados -, a estatística das horas semanais efetivamente trabalhadas indicam, ao longo do período (1989 a 2001), a persistência de elevada proporção, acima de $40 \%$ de assalariados, trabalhando 45 ou mais horas semanais.

Enfim, quase a metade dos trabalhadores assalariados na RMSP tem o seu tempo de vida reduzido a tempo de trabalho - o que é deveras, indício visceral da precarização do trabalho (como observamos acima, não estão incluídos na estatística social de contagem da jornada de trabalho, o tempo de deslocamento do local de trabalho à residência, que consome, no caso das metrópoles, como São Paulo, um tempo significativo da vida de operários e empregados assalariados; muito menos, o tempo de trabalho que permeia o tempo de vida pessoal de assalariados que se submetem irremediavelmente a levar, para casa, tarefas e preocupações dos locais de trabalho).

Os elementos de precarização do trabalho indicados antes (perda do poder de barganha sindical, crescimento do desemprego total, expansão dos contratos de assalariamento precário/flexibilizado) se traduzem, no plano da estatística social, na perda da participação do trabalho na renda nacional. Por exemplo: no período de 1992 a 1998, a repartição do PIB entre trabalho, capital e administração pública demonstra uma significativa inversão de posições. Por exemplo, a remuneração dos empregados (trabalho) que em 1992 era de 44\%, cai para $36 \%$, em 1998. A proporção do excedente operacional bruto (capital) que era de $38 \%$ em 1992, sobe para $44 \%$, em 1998. O rendimento dos trabalhadores autônomos estagnou-se no período em torno de 6\% (DIEESE, 2002). Enfim, são elementos objetivos de precarização do trabalho que atingem o conjunto do proletariado brasileiro, alterando o metabolismo social do trabalho no Brasil.
Ao mesmo tempo, a perda da participação do trabalho na renda nacional ocorreu num período histórico de crescimento exacerbado da produtividade do trabalho em setores industriais e serviços da economia brasileira, com destaque para os loci de redundância do trabalho vivo, isto é, os setores mais dinâmicos da indústria - por exemplo, a indústria automotiva e os serviços financeiros e creditícios.

Apesar do índice de crescimento medíocre da economia brasileira na década de 1990, cresceu, no período, tanto na indústria, como nos serviços mais dinâmicos, como o setor creditício e financeiro, a "produtividade do trabalho", por conta das inovações tecnológico-organizacionais de cariz sistêmico. O que significa que, num contexto de perda de poder de barganha sindical, exacerbou-se, numa dimensão inaudita, a extração da mais valia relativa (ao mesmo tempo, o crescimento das horas extras atingiu amplos contingentes de assalariados dos setores mais dinâmicas da economia brasileira - o que significa que, no Brasil, o hipermoderno articula-se atavicamente com o atrasado, ou seja, a exploração através da mais valia relativa articula-se, ontogeneticamente, com a extração por meio da mais valia absoluta).

\section{Considerações finais}

O que conseguimos apreender é que a reestruturação capitalista no Brasil sob a era neoliberal constituiu, no decorrer da década passada, uma nova morfologia social de acumulação capitalista baseada na "lógica da redundância do trabalho vivo" (instaurada, seja por meio de cortes de pessoal, seja por meio da contratação precária). Nessa perspectiva, torna-se necessário apreender as novas "experiências da precarização do trabalho" - "experiência percebida" e "experiência vivida", processos dialeticamente articulados, que se impõem aos sujeitos/agentes assalariados em processo de reestruturação. Na verdade, as mudanças estruturais da forma salarial dão origem a uma "experiência transformada da condição salarial", e, como observa Thompson (1963, p. 204), "essa experiência é determinante, no sentido de que exerce pressão sobre a consciência social existente, propõe novas questões e oferece grande parte do material com que lidam os exercícios intelectuais mais elaborados".

\section{Referências}

ALVES, G. O novo (e precário) mundo do trabalho: reestruturação produtiva e crise do sindicalismo. São Paulo: Boitempo, 2000.

. Dimensões da reestruturação produtiva. Londrina: Práxis, 2007. 
BRASIL. IBGE. Sindicatos: Indicadores sociais 2003. Disponível em: <http://www.ibge.gov.br/home/estatistica/ populacao/condicaodevida/indicadoresminimos/ sinteseindicsociais2003/default.shtm $>$. Acesso em: 30 jan. 2009.

CAPPA, J. Balanço das negociações coletivas de trabalho no Brasil nos anos 90. Cadernos da FACECA, Campinas, v. 11, n. 1,2002

DIEESE. A situação do trabalho no Brasil: um balanço dos anos 90. São Paulo: 2002.

2001.

Os rendimentos do trabalho no Brasil. São Paulo:

HOFFMAN, M. B. P.; MENDONÇA, S. E. A. O mercado de trabalho na região metropolitana de São Paulo. Estudos Avançados, São Paulo, USP, v. 17, n. 47, 2003.

HARVEY, D. A condição pós-moderna. São Paulo: Loyola, 1992.

LUKÁCS, G. Ontologia dell'essere sociale. Roma: Riuniti, 1981. (3v).

MARX, K. Salário, preço e lucro. São Paulo: Vértice, 1988. THOMPSON, E. P. A formação da classe operária inglesa. Rio de Janeiro: Paz e Terra, 1963.

\section{Giovanni Antonio Pinto Alves}

giovanni.alves@uol.com.br

Doutorado em Ciências Sociais pela Universidade Estadual de Campinas (Unicamp)

Professor livre-docente de Sociologia no Departamento de Sociologia e Antropologia, Universidade Estadual Paulista Júlio de Mesquita Filho (Unesp)

\section{Unesp, Campus Marília}

Departamento de Sociologia e Antropologia

Av. Hygino Muzzi Filho, 737

Caixa Postal: 181

Marília - São Paulo - Brasil

CEP: $17525-900$ 